\title{
4 A LOUCURA E SUA VERDADE EM QUESTÃO: DISCURSOS DE PROFISSIONAIS DE ENFERMAGEM DA ATENÇÃO HOSPITALAR
}

\author{
Ludmila de Moraes¹; Edirlei dos Santos²; Helca Reis ${ }^{3}$; Marianna Silva4; Paula Vianna ${ }^{5}$; Teresa Kurimoto ${ }^{6}$ |
}

\section{RESUMO}

Tomou-se por objetivo analisar os discursos de profissionais de enfermagem de uma instituição hospitalar acerca da loucura e do cuidado de enfermagem voltado a pessoas com sofrimento mental. Trata-se de pesquisa de abordagem qualitativa, de caráter exploratório, tomando o Modo Psicossocial por arcabouço teórico sendo entrevistados 17 profissionais de Enfermagem da atenção hospitalar especializada em psiquiatria. Os dados foram analisados pela Análise de Conteúdo sendo usadas as técnicas de Análise Temática e Análise de Enunciação. Emergiram duas categorias: (1) Concepções e causalidades: entre o concreto da teoria e o abstrato da experiência; na qual discute-se o silenciamento da experiência diante da teoria que acaba por prevalecer quando se busca saber o que é a loucura. (2) A (in)visibilidade revisitada ou a exclusão como regra na qual a invisibilidade da loucura reaparece na forma da loucura falsa. A presença de discursos destoantes do preconizado pela política nacional de saúde mental incita à reflexão acerca da formação de profissionais de enfermagem no contexto atual, bem como da atenção em rede de base comunitária.

\section{PALAVRAS-CHAVE: Saúde mental; Enfermagem psiquiátrica; Cuidados de enfermagem; Doença mental}

\section{RESUMEN}

\section{"La locura y su verdad en cuestión: Discursos de profesionales} de enfermería del hospital“

El objetivo de este artículo es analizar los discursos de profesionales de enfermería de una institución hospitalaria acerca de la locura y del cuidado de enfermería dirigido a personas con sufrimiento mental. Se trata de una investigación de abordaje cualitativo, de carácter exploratorio, tomando el Modo Psicosocial por marco teórico siendo entrevistados 17 profesionales de Enfermería de la atención hospitalaria especializada en psiquiatría. Los datos fueron analizados por el Análisis de Contenidos siendo utilizadas las técnicas de Análisis Temática y Análisis de Enunciación. Surgido dos categorías: (1) Concepciones y causalidad: entre la concreción de la teoría y el abstracto de la experiencia; en la que se discute el silenciamiento de la experiencia ante la teoría que acaba por prevalecer cuando se busca saber lo que es la locura. $\mathrm{La}$ (in) visibilidad revisitada o la exclusión como regla en la cual la invisibilidad de la locura reaparece en la forma de la falsa locura. La presencia de discursos similares a los de los primordios de la atención psiquiátrica incita a la reflexión acerca del cuidado y la formación de profesionales de enfermería en el contexto actual así como de la atención en red de base comunitaria

DESCRIPTORES: Salud mental; Enfermería psiquiátrica; Atención de enfermería; Transtornos mentales

\section{ABSTRACT \\ "Madness and its truth in question: Discourses of hospital nurs- ing professionals"}

The objective of this study was to analyze the discourses of nursing professionals from a hospital about mental illness and nursing care for people with mental suffering.

This is a qualitative, exploratory research, with the Psychosocial Mode by theoretical framework being interviewed 17 Nursing professionals of the psychiatric hospital. The data were analyzed by Content Analysis using the techniques of Thematic Analysis and Analysis of Enunciation. Two categories were extracted: (1) Conceptions and causalities: between the concrete of theory and the abstract of experience; which discusses the silencing of the experience before the theory that ends up prevailing when one seeks to know what mental illness. (2) Invisibility revisited or exclusion as a rule in which the invisibility of madness reappears in the form of false madness. The presence of speeches similar to those of the early days of mental health care encourages reflection on the care and training of nursing professionals in the current context as well as community-based network care

\section{KEYWORDS: Mental health; Psychiatric nursing; Nursing care; Mental disorders}

Submetido em 30-09-2017

Aceite em 18-12-2017

\footnotetext{
1 Bacharel em Enfermagem; Enfermeira no Hospital Sofia Feldman, 31844-130 Belo Horizonte, Minas Gerais, Brasil, milanunes2004@yahoo.com.br 2 Enfermeiro; Doutor em Enfermagem; Professor Adjunto na Universidade Federal de Mato Grosso do Sul, Curso de Enfermagem, Brasil, edirlei.machado@ufms.br 3 Enfermeira; Doutoranda em Enfermagem; Professora Assistente na Universidade Federal da Bahia, Instituto Multidisciplinar em Saúde, Bahia, Brasil, helcareis@gmail.com 4 Aluna na Universidade Federal de Minas Gerais, Curso de Graduação em Enfermagem, 31270-901 Belo Horizonte, Minas Gerais, Brasil, mari_roberta3005@hotmail.com 5 Enfermeira; Doutora em Enfermagem; Professora Associada aposentada Universidade Federal de Minas Gerais, Escola de Enfermagem, Brasil, paulacmv@gmail.com 6 Enfermeira; Psicóloga; Doutora em Enfermagem; Professora Adjunta na Universidade Federal de Minas Gerais, Escola de Enfermagem, Brasil, teresac@ufmg.br
} 


\section{INTRODUÇÃO}

O campo da saúde mental no Brasil vem passando por diversas mudanças e, a despeito de trazer a marca de uma ousada, complexa e desafiadora política de saúde mental, sabe-se que é fundamental a perspectiva de construção permanente de práticas inovadoras de cuidado (Ministério da Saúde, 2015). Com a Reforma Psiquiátrica Brasileira empreende-se um conjunto de transformações, das quais destaca-se a exigência de a sociedade em geral repensar as concepções acerca da relação saúde e doença mental, o que implica numa mudança das relações entre cultura e loucura (Fonseca e Jaeger, 2015).

Depreende-se, assim, "que a luta por um atendimento resolutivo, integral e humanizado para a população que padece de sofrimento psíquico passa pelo reconhecimento desses sujeitos como cidadãos que gozam do direito de buscar ajuda dispondo de uma rede de atenção com diferentes serviços a serem acessados em diferentes circunstâncias de suas vidas, quando julgarem necessário" (Ministério da Saúde, 2015, p. 8).

Para além do acesso aos serviços, luta-se nos diferentes espaços e movimentos sociais por uma cidadania que se distancia da submissão ou sujeição a um modelo predefinido de cidadão, para reencontrá-lo na perspectiva do respeito às diferenças e à autonomia (Macedo, Abreu, Fontenele e Dimenstein, 2017).

A Política Nacional de Saúde Mental investe na criação de uma Rede de Atenção Psicossocial (RAPS) contando com serviços abertos de base comunitária. Uma rede integrada e diversificada composta por Centros de Atenção Psicossocial (CAPS), ações de saúde mental na atenção primária a saúde e programas intersetoriais que fomentam a arte, cultura e renda, como recurso terapêutico. (Ministério da Saúde, 2011)

Nesse cenário, coexistem avanços e desafios. Incluise como desafio a atenção às pessoas em situação de abuso de álcool e outras drogas. "As teses defendidas por muitos, e também promulgadas pelos meios de comunicação, revelam concepções e crenças de que essas pessoas precisam de internação para se reorganizar, ou 'se recuperar', apanágio do discurso de muitas clínicas de 'recuperação de dependentes químicos"' (Assis, Barreiros, e Conceição, 2013, p. 585-6).

Nesse contexto, segundo Estrela e Loyola (2014), a enfermagem que atua nos serviços de saúde mental, considerando seu perfil de trabalho baseado em plantões e na permanência, tem grande papel na promoção da reabilitação.
Sabe-se, entretanto, que o cuidado ao sujeito que sofre está diretamente relacionado com as concepções que o profissional constrói para si.

Sabe-se ainda que: "A consolidação da reforma psiquiátrica brasileira implica em transformar saberes e práticas em relação à loucura, perceber a complexidade do objeto de intervenção, (re)compreender o sofrimento psíquico, e efetivamente destruir manicômios externos e internos que têm permitido a constituição de determinadas formas de pensar e agir e, fundamentalmente, reinventar modos de se lidar com a realidade" (Kantorski, 2012, p. 10).

Nesse cenário, pode-se dizer que os serviços hospitalares de atenção psiquiátrica, serviços cuja existência precede a lei que regulamenta a política nacional de saúde mental, acompanharam esses movimentos de inovação de práticas de atenção em saúde mental? Tomou-se por objetivo desse estudo compreender a(s) concepção(ões) de loucura construídas por profissionais de enfermagem de uma instituição hospitalar psiquiátrica.

Acredita-se que, conhecendo tais discursos, possa-se compreender os princípios que norteiam as práticas de enfermagem nas instituições hospitalares psiquiátricas, em especial, em suas condutas e decisões sobre o cuidado de enfermagem a pessoa em sofrimento mental. Essa compreensão pode trazer contribuições importantes para as propostas de educação permanente, para a formação dos profissionais de enfermagem e para as práticas de enfermagem no contexto atual.

\section{MÉTODOS}

Trata-se de pesquisa de abordagem qualitativa, de caráter exploratório, tomando o Modo Psicossocial por arcabouço teórico.

O presente estudo foi realizado em um serviço hospitalar especializado, público e estadual, situado em Belo Horizonte, estado de Minas Gerais - Brasil. Participaram da presente pesquisa 17 profissionais de enfermagem, constituindo uma Amostragem Intencional (Creswell, 2014).

Intencional, por serem aqueles que teriam as informações consoantes ao objeto de estudo da presente pesquisa.

Adotou-se como critério de inclusão os profissionais de enfermagem que trabalhavam há mais de um ano no cuidado direto ao usuário com sofrimento mental, sendo excluídos os que não possuíam esse tempo de experiência. 
A partir desse critério, foram entrevistados sete Técnicos de Enfermagem (profissionais de enfermagem de nível médio) e dez Enfermeiros do mesmo hospital especializado (hospital psiquiátrico) que atuam em unidades de internação (duas masculinas e duas femininas), unidade de urgência e unidade de cuidados clínicos (voltada a pessoas com sofrimento mental grave e em crise que apresentam comorbilidades clínicas). Esses profissionais serão identificados no presente artigo pelas siglas TE e E seguidas por número ordinal de acordo com a ordem de realização da entrevista.

A coleta de dados foi realizada no período outubronovembro de 2016, consistindo em entrevista semiestruturada. As entrevistas foram gravadas, transcritas na íntegra. Os dados foram analisados pela Análise de Conteúdo, com as técnicas de Análise Temática e Análise de Enunciação segundo Bardin (1977). Dessa análise emergiram duas categorias: (1) - Concepções e causalidades: entre o concreto da teoria e o abstrato da experiência. (2) A (in)visibilidade revisitada ou a exclusão como regra. Os participantes, devidamente informados, após concordarem, assinaram o Termo de Consentimento Livre e Esclarecido (TCLE). Todos os aspectos éticos foram respeitados, conforme a resolução CNS 466/2012. O estudo foi aprovado pelo Comitê de Ética em Pesquisa da Universidade Federal de Minas Gerais, CAAE n. 46301615.1.0000.5149 e pelo Comitê de Ética e Pesquisa da instituição pesquisada.

\section{RESULTADOS E DISCUSSÃO}

\section{Concepções e Causalidades: Entre o Concreto da Teoria e o Abstrato da Experiência}

Foucault (1961) afirma que a origem da loucura é bem remota. Tão remota quanto o surgimento da loucura, são as concepções sobre ela. Para responder ao questionamento sobre a concepção de loucura, observa-se que os profissionais encaminham suas respostas na direção da etiologia, muitas delas contraditórias entre si. Os entrevistados associaram às suas concepções de loucura, ideias de suas possíveis causas, sendo estas múltiplas e com vários significados.

"Então, a loucura pode vir de uma série de coisas." TE3 "Pessoas que já vem com aquela carga hereditária e um evento traumático faz com que ela surte." E4

"Bom, cientificamente, os transtornos mentais, tem algo de hereditário e também eu acho que pode ser desencadeado pelo uso de substância psicoativa e por problemas ambientais, emocionais.” E1
A visão multicausal é algo que se encontra na literatura científica, uma vez que se entende a loucura como um fenômeno complexo, embora passível de explicação. Observa-se que essas falas buscam na lógica da causa e efeito seu modo de conceber a loucura, tal como se observa em estudos voltados para a lógica psiquiátrica (Araújo e Banzato, 2014).

Ainda que complexa, as diferentes concepções de loucura foram organizadas em um clássico estudo. De acordo com Pessotti (1994) as concepções de loucura se organizam em três modelos: mitológico, psicológico-passional e organicista. "De Homero até a tragédia grega, predomina a primeira perspectiva: temos um enfoque mitológico-religioso da loucura. Entre os trágicos, principalmente na obra de Eurípides, instaura-se a concepção passional, psicológica dos desvarios. De Hipócrates a Galeno consolida-se uma doutrina rigidamente organicista da insensatez ou da des-razão." (Pessotti, 1994, p. 78) Pessotti (1994) afirma que esses três modelos explicativos da loucura vêm, ao longo da história sendo recorrentes, estando presentes, inclusive, nas concepções mais atuais. Nas concepções dos entrevistados observa-se que ideias desses três modelos se encontram presentes.

No enfoque mitológico-religioso o homem é passivo diante da vontade divina. O homem, submetido a vontade dos deuses, torna-se louco. Alguns entrevistados apresentam concepções próximas a essa:

“Acredito - é pensamento meu - que é uma doença bem espiritual. Espiritual com relação a obsessão. Acho que $80 \%$ da doença mental ela é obsessiva. Aí no caso, cada um pensa e age como quiser, mas eu tenho muito exemplo e muito como confirmar isso." TE2

É interessante observar que, se a loucura é vontade dos deuses, o homem não pode fazer nada para modificar tal fato. Essa ideia, segundo Pessotti (1994), acaba gerando na sociedade uma maior tolerância com as 'incoerências e instabilidades' do doente, mas, ao mesmo tempo, reforça outra ideia: a de submissão do sujeito à um poder maior, consequentemente, as possíveis saídas para lidar com o sofrimento são também externas ao sujeito. Tal lógica, pode embasar práticas de cuidado em que o sujeito, fragilizado ou anulado, nada pode fazer em prol de si mesmo, posto que, se a loucura advém de fontes externas à ele, o tratamento assim também deve ser. Já a vertente psicológica-passional, de acordo com o pensamento de Eurípides, propõe que a loucura não advém somente dos deuses. 
Pessotti (1994) afirma que Eurípides não teorizou o termo loucura, mas os personagens de suas obras sempre trouxeram mudanças emocionais, alienações, desajustamento emocional, dentre outras formas de loucura, que vemos nos dias de hoje. A loucura, nessa perspectiva é entendida como "produto de conflitos, mas trata-se de conflitos interiores, entre paixões e a norma, a razão e o instinto, entre amores conflitantes, entre ódios e afetos ou entre desejo e vergonha" (Pessotti, 1994, p. 30). Tal vertente está presente nos fragmentos de algumas entrevistas, tais como:

"Assim, às vezes, a pessoa... ela só precisa da chave pra abrir o cadeado. Então, às vezes, alguns [ficam loucos] por desilusões amorosas, outros por perda de alguém, de algum parente." TE3

"Surge do nada. A linha da razão e da loucura é muito tênue. Qualquer pessoa pode ficar doente [...] Eu acho que loucura é quando a gente perde esse equilíbrio [...] as vezes, falta de controle mesmo."TE4.

A terceira vertente chamada vertente organicista foi pensada por Hipócrates. A doutrina hipocrática propõe que a loucura seja entendida como desordem corporal e orgânica. Tal desordem, vem dos processos de perda de razão e perda de controle emocional. "A loucura, como doença que é, resulta de crise no sistema dos humores. É uma doença orgânica." (Pessotti, 1994, p. 48) Tal pensamento é disseminado no ramo da medicina desde o século XVIII e muito presente nos dias de hoje, embora, com o passar do tempo e a produção de saberes, surge numa mistura de visão orgânica ou genética associada à algum fator, subjetivo ou externo ao sujeito, que coloca o 'mecanismo orgânico' previamente existente, para funcionar (Pessotti, 1994). Essa forma de pensar a loucura ficou evidenciada, com frequência, nos discursos dos entrevistados, como se pode ver nas falas seguintes:

"A loucura é uma doença muito subjetiva e de difícil acerto do tratamento, porque, muitas vezes, depois do diagnóstico o médico vai testando as drogas (...) Tem umas que (...) vem da genética e tem outras que são desencadeadas pelo uso de droga" TE2

"Eu acho que loucura é quando a gente perde esse equilíbrio ou é alguma coisa hereditária..." TE3

"A loucura, hummm, ela vem pelo vicio, né, de algum, de algum, vício, de crack ou da bebida alcoólica. Mas já tem as pré-existentes que eu acredito que seja hereditário."TE5
“Todos nós estamos sujeitos a ela (à loucura). Claro que umas pessoas mais e outras menos. Pessoas que já vem com aquela carga hereditária e um evento traumático faz com que ela surte" E4

Curiosamente, a ideia de que loucura se inscreve como algo humano, a qual 'todos nós estamos sujeitos', é logo exorcizada por determinantes concretos provenientes dos genes ou das drogas. Nessa condição, a loucura torna-se, novamente, limitada à uns poucos. Nesse movimento pendular de democratização da loucura - para todos - e delimitação de um público alvo - quem tem carga genética - surge como um elemento a mais, o fator social.

Assim, aspectos que se articulam a fatores sociais inerentes ao meio em que a pessoa vive e convive emergiram como fatores contributivos para a o aparecimento do sofrimento mental. Além disso, apenas um participante propõe que a loucura, para além dos determinantes sociais ou biológicos, traga em si algo da particularidade como uma determinada pessoa significa um acontecimento.

"Eu não penso que é hereditário, 'a, na sua família tem várias pessoas doentes.' Eu penso que não é assim. Eu penso que qualquer pessoa pode ficar doente. Essa régua aqui pode cair no chão e pra mim ela tem um efeito, pra você ela tem outro. Pode ter um acidente bravo na rua, um acidente grave, o seu olhar, seu olhar, pra ele é um, o meu é outro. O meu entender é um, o seu é outro. Eu penso que pessoas que são normais, né, entre aspas, vê as coisas e não consegue lidar com aquilo. $\mathrm{E}$ isso pode desencadear." TE4

Paralelamente ou como um desdobramento dessas concepções, encontram-se outras que trazem marcadamente a influência do discurso da saúde, representado pelo discurso preventivista ou por seu correlato, o discurso do risco.

“Olha, eu acho que é uma doença que qualquer um está sujeito a ela e que a gente tem que está bem atenta, principalmente a prevenção, a forma de viver para tentar minimizar esse risco desse adoecimento." E1

Novamente, se a loucura aparece como uma condição que não poupa a ninguém e, ainda que seja enigmática, ela exige que algo possa ser feito. 
Nessa direção, o discurso da prevenção e do risco acenam para a possibilidade de que 'qualquer um' pode vir a ser louco e esse fato pode trazer em si a exigência de enfrentamento: descobrir uma forma de viver melhor para evitar esse risco. Sabe-se que foi no século passado que a noção de risco se torna presente e importante no discurso médico. Para Baságlia (2010), entretanto, esse discurso aparece mais na direção de dilatar o campo da doença do que de reduzi-lo. Compreende-se que esse discurso sobre a prevenção traz em si mais do que a ideia de se defender da doença. $\mathrm{O}$ ato de prevenir, nesse contexto, resulta da ideia de que estejamos diante de um mal que não se volta à uns poucos, mas que pode atingir a qualquer um. Contra essa fragilidade que assombra, encontrar formas de proteção acaba sendo um modo de lidar com a realidade. Em especial, quando se entende que "A loucura é um mal incurável! É o mal do século!” TE4

A questão que se coloca é que o discurso da prevenção, em outros tempos, embasou propostas, de que a atenção a doença mental deveria ir além dos muros dos hospitais chegando à comunidade. Isso implicou, à época, propostas de uma identificação precoce de indivíduos propensos a desenvolver doenças mentais para que se pudesse precocemente diagnosticar e reabilitar. Entretanto, dessa iniciativa, a princípio considerada inovadora, sobreveio a lógica de um cuidado que se pautava na adaptação das pessoas em sofrimento à um padrão normativo preexistente e, aos não acometidos pela loucura, um convite ao controle de si (Jeferino, Rodrigues e Assis, 2015). Perspectivas essas que trazem em si uma impossibilidade, quando pensadas de forma completa ou total, ou seja, há uma impossibilidade concreta na proposta de se adaptar um cidadão a todos os padrões de uma dada sociedade ou mesmo quando se propõe que a pessoa tenha controle absoluto sobre si. Retomando as concepções de loucura, identificou-se que, ao elucidar suas concepções de loucura, os participantes recorreram aos sentimentos que a loucura desperta neles:

"Olha, na minha cabeça é uma coisa muito triste. Ainda mais pelo que a gente vê aqui, o que os pacientes passam, o que a gente passa com eles (...) Eu resumiria em tristeza. Eu acho muito triste, essa questão do paciente louco." TE1

"Mas realmente é triste a pessoa perder a capacidade de discernimento, de autocuidado, de dizer sim ou não, a capacidade de ir e vir. Realmente, a loucura, de todas as doenças que a gente vê aí, sejam elas clinicas, eu acho que a loucura é das piores." E10
Os participantes, para falar de suas concepções de loucura, usam termos: triste, difícil, mal. Essa forma de pensar a loucura relaciona-se, em parte, com o estigma que ela sempre carregou. Sabe-se que esse estigma figura para a pessoa com sofrimento mental como fontes de sofrimento, criando barreiras para realização de projetos pessoais e obstáculos no acesso ao cuidado a saúde. (Ministério da Saúde, 2015). É interessante observar que o estigma reaparece na forma de uma tristeza, compartilhada pelo profissional ('o que a gente passa com eles'), por vezes conectada à desrazão e ausência de autonomia, o que a coloca como o pior dos males. Nos dizeres de Foucault (1961) esse é um legado que a psiquiatria clássica nos deixa: a oscilação entre dois domínios, a saber, o do concreto da teoria e o do abstrato da experiência da loucura.

Assim: "Não é o conflito entre experiência e teoria, entre a familiaridade e o saber abstrato, o bem conhecido e o conhecido; de um modo mais secreto, é um dilaceramento na experiência, que tivemos e talvez tenhamos sempre, da loucura - dilaceramento que separa a loucura considerada por nossa ciência como doença mental daquilo que ela pode entregar de si mesma no espaço em que nossa cultura a alienou" (Foucault, 1961, p.431).Tantos anos decorridos dessa análise foucaultiana e podemos encontrar nela a atualidade comprovada pelos discursos de trabalhadores de uma instituição hospitalar a qual acorrem pessoas em sofrimento mental grave em crise. Atualidade essa não sem consequência para as práticas de cuidado que ali tem lugar.

\section{A (In)visibilidade Revisitada ou a Exclusão como Regra}

A construção de concepções acerca da loucura por profissionais de enfermagem, a partir das falas desses mesmos profissionais, é um trabalho que parece se dar, marcadamente, por fragmentos de teorias estudadas ou apreendidas nas discussões clínicas cotidianas. Durante a análise das entrevistas, emergiu, outra forma muito peculiar desses profissionais pensarem loucura.

"O doente mental em si, a doença mesmo, ela é até prazerosa trabalhar com ela." TE6

Corroborando achados de outro estudo (Guimarães, Borba, Maftum, Larocca, e Nimtz, 2015), identifica-se essa percepção de ser fácil cuidar de uma pessoa com uma doença mental, ainda que em crise e internada. Entretanto, chama a atenção, o enfoque dado na fala ao doente e sua 'doença mesmo'. 
Enfocando essa ideia - de uma 'doença mesmo' - resgata-se Foucault (1961, p. 430), quando compreende que a apropriação da loucura como matéria médica acaba por produzir, a despeito de exclusões, um espaço em que a loucura fala por si mesma: "Mas, de um lado, com a medicina, temos o trabalho do conhecimento que trata as formas da loucura como outras tantas espécies naturais; do outro, um esforço de reconhecimento com o qual, de certa forma, se deixa a loucura falar, ela mesma, e fazer ouvir vozes que, pela primeira vez na história do Ocidente cristão, não serão nem as da profecia, nem as do transe ou da possessão, nem as da bufonaria; vozes nas quais a loucura não fala nem por outra coisa, nem por outra pessoa, mas por si mesma. No silêncio do internamento, a loucura conquistou estranhamente uma linguagem que é a sua". (Foucault, 1961, p. 430)

É então desse lugar que se revisita a loucura e o louco em sua verdade, em sua essência: uma loucura mesmo, uma doença mesmo. Ou, melhor dizendo, em seu ofício de cuidar o profissional constrói para si uma essência da loucura que ele espera, a despeito das diferenças individuais reconhecidas, reencontrar em cada paciente de quem ele cuida.

Tomando o trabalho, aqui entendido como cuidar de usuários com sofrimento mental em crise, pelo viés do prazer, transparece na fala o trabalho com a doença. Doença entendida como sinônimo do doente, uma vez que o cuidado volta-se a ela.

Ao reforçar a qual doença se refere - a doença mesmo - entrevê-se, ainda, nessa fala uma outra visão das formas de adoecer que não se configura ou não merece $o$ status de doença.

Essa ideia é reencontrada e melhor explicada em falas de outros participantes:

"Pacientes "loucos" a gente não está tendo. Os loucos mesmo a gente não está tendo. A maioria está sendo pacientes judiciários que são dependentes químicos, que estão tomando... eu diria que eles estão tomando o lugar deles [dos loucos mesmo]" TE3

"Loucura, loucura, loucura mesmo, eu acredito que eu vi poucas aqui. Eu vi muitas simulações, muitos pacientes que, no caso, usuários de droga, simulam muuuuito." TE6

'Isso' que não faz jus ao status de doença, aparece como algo para além (ou aquém) da loucura.
Ao se tornarem 'dependentes químicos', 'usuários de drogas' essas pessoas deixam de serem vistas como doentes, tornando-se simuladores, pessoas que falseiam o que sentem. Nessa concepção, as pessoas que ali estão em função de sua condição de abuso de drogas, passam a não merecer crédito em suas queixas e, possivelmente, por dedução, não merecerem o cuidado. A invisibilidade do sofrimento acaba por ser um elemento decisivo para esse julgamento.

“O paciente dependente químico não. Ele usou a droga ali, ele tá louco naquele momento. A partir do momento que passou o efeito da droga ele tá no efeito da lucidez. [...] Apesar deles terem entrado com CID (Código da Classificação Internacional de Doenças) da saúde mental, [...] quando eles saem dessa crise, né, da loucura da dependência química, devida a, como diz, a droga que ele, que, usou ali...” TE3

Os profissionais, assumindo a condição de juízes, embasados em suas experiências e conhecimentos, sentenciam o que é loucura mesmo ou loucura simulada. Ou ainda, criam a classificação de uma loucura da dependência química. Tal prática entreabre a possibilidade de uma concepção moral do cuidado a qual baseia-se no julgamento tácito definindo quem merece ou não.

Situações dessa natureza, por vezes, "correspondem a práticas clínicas, ofertadas muitas vezes de maneira compulsória por alguns trabalhadores de saúde, que envolvem descasos, incapacidade de escuta ou até negligência..." (Ministério da Saúde, 2015, p. 292). Tais práticas clínicas, podem ter como pano de fundo o medo e a insegurança do profissional:

“... porque hoje o drogadito ele se torna um doente mental por causa do uso da droga. E lidar com esse tipo de paciente não é muito fácil. Porque eles tentam, eles te ameaçam o tempo todo, eles te manipulam o tempo todo. Então você tem que ter muito jogo de cintura pra não te influenciar em nada e saber lidar com esse tipo de paciente pra poder realmente fazer todos os cuidados necessários com eles." TE7

Diante dessas concepções de loucura, os autores da presente pesquisa, cunharam a denominação de 'loucura verdadeira' ("Loucura mesmo") e outra, que por ser seu oposto, poderia ser chamada de "loucura falsa ou loucura da dependência química”. 
Essa distinção tem como sustentação lógica o discurso médico psiquiátrico.

A loucura, denominada como verdadeira, é aquela que os profissionais reconhecem em seu caráter patológico, traduzido por diagnósticos psiquiátricos, tais como: esquizofrenia, transtorno bipolar, depressão, entre outros. Pesquisadores críticos dessa prática clínica norteada pelo diagnóstico psiquiátrico problematizam a "prática clínica centrada no diagnóstico de entidades mórbidas - distintas ou dimensionais - do qual decorrem, de maneira quase automática, uma árvore de decisões técnicas e terapêuticas preestabelecidas, sem que a dimensão da singularidade e a escuta do paciente em sua dimensão específica de sujeito desempenhem de fato algum papel efetivo na compreensão e no manejo do fenômeno psicopatológico enquanto tal (Costa Pereira, 2014, p. 1036).

"O esquizofrênico, por exemplo, ele conversa com você, alguns pacientes conversam com você. De repente [...], eles ficam completamente agressivos, como se nada tivesse acontecendo e começa a se agitar de uma forma (...). Já o bipolar, ele é bem diferente. Ele pensa primeiro pra fazer. Já o esquizofrênico, não. E, e, ele rapidamente, como num surto, ele esquece completamente o que ele fez. O bipolar ele não esquece. TE6

Essa lógica de conceber a doença como entidade autônoma data do século XVIII. Assim, "a nosologia passaria a conceber a "doença" como entidade autônoma, independente do sujeito que dela padece, encarnando um mal exterior e com determinações próprias" (Costa Pereira, 2014, p. 1040).

Restaria à pessoa que sofre, nessa lógica, o lugar de assujeitamento e total submissão à essa condição externa que $o$ acomete.

Ao vitimado e não sujeito é concedido o cuidado. Se, por um lado, há uma garantia de crédito em suas queixas, por outro, institui-se um cuidado centrado no profissional e em seus conhecimentos teóricos, sobre o qual as perspectivas de quem é cuidado, suas percepções, pouco contam. Dessa forma, o sujeito, ainda que reconhecido em sua condição de doente verdadeiro (doente mesmo), pode acabar por ser alvo de práticas de cuidado pouco voltadas à autonomia, sendo-lhe negada sua condição de cidadania, de protagonismo no seu tratamento.
Por sua vez, uma "loucura falsa ou da dependência química" instala-se em decorrência do fato dos profissionais não identificarem algum tipo de sofrimento mental ou sintoma cientificamente reconhecido. Podese pensar que, para eles, o usuário de drogas configura-se um tipo de paciente que "procurou a doença" ou então que, como dizem os participantes, está simplesmente simulando o estado de loucura, roubando, com isso, um lugar que não é seu. Mas o fato é que a ausência de padrões já conhecidos como doença mental, faz com que ele seja pensado e cuidado a partir dessa condição de negação.

Trata-se de uma discussão revisitada. Foucault (1961, p. 210) problematizava essa questão da verdade presente na loucura. $\mathrm{O}$ mundo patológico era reconhecido por suas normas, ou seja, por sinais reconhecidos externamente que denunciavam a presença de uma doença. Assim, "Como poderia a loucura ocupar lugar nesse mundo das doenças cuja verdade se enuncia por si mesma nos fenômenos observáveis, enquanto no mundo concreto, ela só se oferece sob seu perfil mais aguçado, o menos suscetível de ser apreendido, isto é, a presença instantânea de um louco, tanto mais percebido como louco na medida em que menos deixa transparecer a verdade aberta da loucura?" (Foucault, 1961, p. 210)

Essa realidade parece se repetir quando, diante de uma pessoa que se encontra numa condição de abuso de drogas, estando sem os efeitos da substância, não exibe os clássicos sintomas que o enquadrariam em algum diagnóstico psiquiátrico já conhecido.

Assim como os loucos do século XVII e XVIII, essas pessoas são excluídas, mas, agora o são exatamente porque não mais trazem mais a marca familiar da loucura. Pode-se também dizer que a concepção de 'loucura falsa' associada a condição de uso ou abuso de drogas, remete à um processo histórico de estigmatização dos usuários. Esse estigma está fortemente relacionado com o proibicionismo, constituído como um fator social e a demonização, criando o estigma de que o dependente químico está transgredindo os padrões da sociedade. A associação que envolve a ilegalidade ao uso dessas substâncias, faz com que esses usuários sejam vistos como criminosos e, portanto, não portadores de problemas de saúde (Paiva, Ferreira, Martins, Barros, e Ronzani, 2014). Outro estudo aponta que essas pessoas acabam sendo vistas como incapazes de um autocontrole tornando-se, assim, "pessoas fracas" sendo-lhes atribuída uma culpabilidade por sua condição (Soares, Vargas e Formigoni, 2013). 
Tais concepções, aproximam-se dos discursos morais e estigmatizantes, gerando descontentamento ou estranhamento aos profissionais:

"Uma das coisas que mudou e eu não tenho gostado é o perfil do paciente. No caso do estou falando do paciente usuário de droga." TE1

"Mas depende muito do perfil do paciente, né, porque o paciente psiquiátrico crônico é uma coisa, já o paciente com doenças secundárias do vício ai já é outra coisa..."TE5

Tal descontentamento pode interferir na forma como o cuidado é pensado ao usuário, pois contem nesse contexto, julgamentos não baseados no conhecimento científico. Assim, a invenção de práticas de cuidado e a construção de saberes acerca desse sujeito ficam comprometidas, na medida em que não há sequer o reconhecimento desse sofrimento e, consequentemente, não há a aposta de que esse sujeito tenha saberes capazes de construir saídas para seu próprio sofrimento.

Chama a atenção, ainda, o fato de que toda a discussão apresentada nessa categoria advém dos discursos produzidos pelos profissionais de enfermagem de nível médio. Sendo eles todos trabalhadores da mesma instituição pode-se inferir a existência de um discurso coletivo consolidado que repercute no cuidado às pessoas em condição de abuso de drogas. Tal fato exige que se repense a formação dos profissionais de nível médio da enfermagem, sabidamente frágil (Fabri e Loyola, 2014) bem como denota a urgência de programas de educação continuada na instituição.

E mais, a inclusão desse profissional nas discussões e práticas clínicas interdisciplinares surgem como exigência ética.

\section{CONCLUSÕES}

A análise dos discursos de profissionais de enfermagem identificou concepções individuais e coletivas consolidadas observando-se que tais discursos são conformados a partir de uma construção sócio-histórica, permeada por experiências ao longo da vida profissional e pessoal. Identificou-se, como contribuição específica desse estudo, a presença de um discurso de negação. Se no século XVIII percebia-se o louco deduzido de sua loucura, agora, percebe-se o objeto droga e deduz-se dele o sujeito e seu sofrimento.
Percebe-se que, a despeito de terem decorrido muitos anos, os avanços alcançados pela luta antimanicomial, consolidados pela política nacional de saúde mental, parecem ter incidido timidamente sobre o discurso e práticas de alguns profissionais. A coexistência de uma atenção baseada na lógica de uma rede assistencial de base comunitária com uma atenção hospitalar psiquiátrica fragilmente articulada com essa rede possibilitam discursos e práticas distintas do que é preconizado.

Em busca de compreender concepções para se compreender práticas, identificou-se que não se pode descontextualizar os discursos dos participantes. Observou-se nos participantes e em seus discursos uma busca genuína por compreender o que se passa com aquelas pessoas sob seus cuidados. Assim, para além da realidade específica dos profissionais de nível médio, depreende-se desse estudo que enfermeiros, enquanto responsáveis técnicos pela equipe de enfermagem; demais profissionais de saúde mental, enquanto membros da equipe multiprofissional que atuam na perspectiva interdisciplinar; gestores da instituição e das políticas de saúde mental no Brasil, devem ler esses discursos como de fragilidades de nossas práticas, que devem ser alvo de políticas de formação e de educação permanente mais consistentes.

\section{IMPLICAÇÕES PARA A PRÁTICA CLÍNICA}

Os discursos dos entrevistados têm fortes influências sobre a concepção de cuidado e a assistência dispensada as pessoas com sofrimento mental. Tais concepções são elaboradas e transmitidas a partir das experiências vividas no ambiente de trabalho e são determinantes para compreender o que esses profissionais entendem sobre reabilitação psicossocial e ideais pós Reforma Psiquiátrica.

Como o cuidado é realizado quando se cuida de alguém que traz algo triste, incurável ou moralmente condenável? Como o cuidado de enfermagem pode se instituir numa situação em que o sujeito e seu sofrimento está ofuscado pelo objeto droga? O presente estudo reforça a urgente necessidade de desconstrução dos manicômios internos, a atualidade da luta pela (re) compreensão do sujeito e seu sofrimento psíquico sem a supremacia do objeto droga, algo que os programas de formação e educação permanente devem enfatizar e priorizar, problematizando as concepções que os alunos trazem consigo. 


\section{REFERÊNCIAS BIBLIOGRÁFICAS}

Araújo, L. F. S. C., e Banzato, C. E. M. (2014). Causas "fracas" e redes causais complexas em psiquiatria. Revista Latinoamericana de Psicopatologia Fundamental, 17(1), 15-28. doi: 10.1590/S1415-47142014000100002

Assis, J. T., Barreiros, G. B., e Conceição, M. I. G. (2013). A internação para usuários de drogas: diálogos com a Reforma Psiquiátrica. Revista Latinoamericana de Psicopatologia Fundamental, 16(4), 584-596. doi: 10.1590/ S1415-47142013000400007

Bardin, L. (1977). Análise de conteúdo. Lisboa: Edições 70.

Basaglia, F. (2010). Carta de Nova York: O doente artificial. In F. Basaglia, Escritos selecionados em saúde mental e reforma psiquiátrica. Rio de Janeiro: Garamond.

Costa Pereira, M. E. (2014). A crise da psiquiatria centrada no diagnóstico e o futuro da clínica psiquiátrica: Psicopatologia, antropologia médica e o sujeito da psicanálise. Physis: Revista de Saúde Coletiva, 24(4), 1035-1052. doi: h10.1590/S0103-73312014000400004 Creswell, J. W. (2014). Investigação qualitativa e projeto de pesquisa: Escolhendo entre cinco abordagens. Porto Alegre: Penso.

Estrela, K. S. R., \& Loyola, C. M. D. (2014). Administration of medication to use when needed and the care of psychiatric nursing. Revista Brasileira de Enfermagem, 67(4), 563-567. doi: 10.1590/0034-7167.2014670410

Fabri, J. M. G., e Loyola, C. M. D. (2014). Desafios e necessidades atuais da enfermagem psiquiátrica. Revista de Enfermagem UFPE on line, 8(3), 695-701. doi: 10.5205/reuol.5149-42141-1-SM.0803201426

Fonseca, T. M. G., e Jaeger, R. L. (2015). A psiquiatrização da vida: Arranjos da loucura hoje. In Ministério da Saúde. Secretaria de Atenção à Saúde. Departamento de Ações Programáticas Estratégicas, Saúde Mental: Humaniza SUS. Brasília: Ministério da Saúde. Acedido em http://bvsms.saude.gov.br/bvs/publicacoes/saude_ mental_volume_5.pdf
Foucault, M. (1961). História da loucura na idade clássica. São Paulo: Perspectiva.

Guimarães, A. N., Borba, L. O., Maftum, M. A., Larocca, L. M., e Nimtz, M. A. (2015). Mudanças na atenção à saúde mental decorrentes da reforma psiquiátrica: Percepções de profissionais de enfermagem. Ciência, Cuidado e Saúde, 14(1), 830-838. doi: 10.4025/cienccuidsaude.v14i1.22187

Kantorski, L. P. (2012). Os desafios da avaliação no campo da saúde mental. Revista Eletrônica de Enfermagem, 14(1), 10-11. Acedido em http://bvsms.saude. gov.br/bvs/publicacoes/saude_mental_volume_5.pdf

Macedo, J. P., Abreu, M. M., Fontenele, M. G., e Dimenstein, M. (2017). A regionalização da saúde mental e os novos desafios da Reforma Psiquiátrica brasileira. Revista Saúde e Sociedade, 26(1), 155-170. doi: 10.1590/ s0104-12902017165827

Ministério da Saúde. Secretaria de Atenção à Saúde. (2011). Avaliação dos hospitais psiquiátricos no âmbito do Sistema Único de Saúde: Ação nacional. Acedido em http://pfdc.pgr.mpf.mp.br/atuacao-e-conteudos-deapoio/publicacoes/saude-mental/avaliacao-dos-hospitais-psiquiatricos-no-ambito-do-SUS-ministerio-dasaude-nov.2011

Ministério da Saúde. (2015). Saúde mental: Caderno HumanizaSUS (5). Brasília: Ministério da Saúde. Acedido em http://bvsms.saude.gov.br/bvs/publicacoes/ saude_mental_volume_5.pdf

Paiva, F. S., Ferreira, M. L., Martins, M. Z. F., Barros, S. L. C. F., e Ronzani, T. M. (2014). A percepção profissional e comunitária sobre a reinserção social dos usuários de drogas. Psicologia \& Sociedade, 26(3), 696706. doi: 10.1590/S0102-71822014000300018

Pessotti, I. (1994). A loucura e as épocas. Rio de Janeiro: Editora 34.

Soares, J., Vargas, D., e Formigoni, M. L. O. S. (2013). Atitudes e conhecimentos de enfermeiros frente ao álcool e problemas associados: Impacto de uma intervenção educativa. Revista da Escola de Enfermagem da Universidade de São Paulo, 47(5), 1178-1185. doi: 10.1590/S0080-623420130000500023 